\title{
Review Article \\ Physiological Implications of Hydrogen Sulfide in Plants: Pleasant Exploration behind Its Unpleasant Odour
}

\author{
Zhuping Jin ${ }^{1,2}$ and Yanxi Pei ${ }^{1}$ \\ ${ }^{1}$ School of Life Science, Shanxi University, Taiyuan 030006, China \\ ${ }^{2}$ School of Chemical Engineering and Environment, North University of China, Taiyuan 030051, China \\ Correspondence should be addressed to Yanxi Pei; peiyanxi@sxu.edu.cn
}

Received 27 November 2014; Accepted 16 February 2015

Academic Editor: David Pattison

Copyright (c) 2015 Z. Jin and Y. Pei. This is an open access article distributed under the Creative Commons Attribution License, which permits unrestricted use, distribution, and reproduction in any medium, provided the original work is properly cited.

\begin{abstract}
Recently, overwhelming evidence has proven that hydrogen sulfide $\left(\mathrm{H}_{2} \mathrm{~S}\right)$, which was identified as a gasotransmitter in animals, plays important roles in diverse physiological processes in plants as well. With the discovery and systematic classification of the enzymes producing $\mathrm{H}_{2} \mathrm{~S}$ in vivo, a better understanding of the mechanisms by which $\mathrm{H}_{2} \mathrm{~S}$ influences plant responses to various stimuli was reached. There are many functions of $\mathrm{H}_{2} \mathrm{~S}$, including the modulation of defense responses and plant growth and development, as well as the regulation of senescence and maturation. Additionally, mounting evidence indicates that $\mathrm{H}_{2} \mathrm{~S}$ signaling interacts with plant hormones, hydrogen peroxide, nitric oxide, carbon monoxide, and other molecules in signaling pathways.
\end{abstract}

\section{Introduction}

Hydrogen sulfide $\left(\mathrm{H}_{2} \mathrm{~S}\right)$ is a colorless, flammable gas with the characteristic odor of rotten eggs. It was widely considered to be just a toxic gas for nearly 300 years mostly due to its unpleasant smell. The breakthrough in the effort to link endogenous $\mathrm{H}_{2} \mathrm{~S}$ levels and functional changes came when the possible role of $\mathrm{H}_{2} \mathrm{~S}$ as an endogenous neuromodulator in the brain was reported [1]. The focus on enzymes generating $\mathrm{H}_{2} \mathrm{~S}$ was another breakthrough in 2001 [2]. The initial work concluded that $\mathrm{H}_{2} \mathrm{~S}$ was a physiological vasodilator and regulator of blood pressure, which stimulated research on $\mathrm{H}_{2} \mathrm{~S}$ physiology [3]. In plants, $\mathrm{H}_{2} \mathrm{~S}$ has been revealed as a crucial player in the regulation of normal plant physiological processes, including seed germination, root morphogenesis, photosynthesis, and flower senescence [4-8]. It was also shown to be an important messenger in plant defense signaling against various abiotic stresses at physiological concentrations [9-13]. In this review, we discuss recent progress that increases our understanding of $\mathrm{H}_{2} \mathrm{~S}$ synthesis and signaling functions in plants.

\section{2. $\mathrm{H}_{2} \mathrm{~S}$ Synthesis}

In mammalian cells, $\mathrm{H}_{2} \mathrm{~S}$ is physiologically generated by pyridoxal- $5^{\prime}$-phosphate-dependent enzymes, including cystathionine beta-synthase, cystathionine gamma-lyase, and 3-mercaptopyruvate sulfurtransferase (3-MST), during cysteine (Cys) metabolism $[3,14] . \mathrm{H}_{2} \mathrm{~S}$ is generated in plants via both enzymatic and nonenzymatic pathways, although the latter only accounts for a small portion of $\mathrm{H}_{2} \mathrm{~S}$ production. Figure 1, with the enzymes highlighted, demonstrates the production of $\mathrm{H}_{2} \mathrm{~S}$ in Arabidopsis thaliana.

Several candidate Cys-degrading enzymes have been reported to exist in different plant species (shown in Table 1). In the model plant $A$. thaliana, the enzymes that produce $\mathrm{H}_{2} \mathrm{~S}$ can be roughly divided into two categories. One class of these enzymes is Cys desulfhydrases (CDes), which degrade Cys into $\mathrm{H}_{2} \mathrm{~S}$, ammonia, and pyruvate in a stoichiometric ratio of $1: 1: 1$ and require pyridoxal $5^{\prime}$-phosphate as a cofactor [15]. L-Cys desulfhydrase is one of the enzymes that decompose L-Cys and was first discovered in the sulfur metabolism of tobacco cultured cells [16]. D-Cys desulfhydrase 1 specifically uses D-Cys as its substrate, and D-Cys desulfhydrase 2 


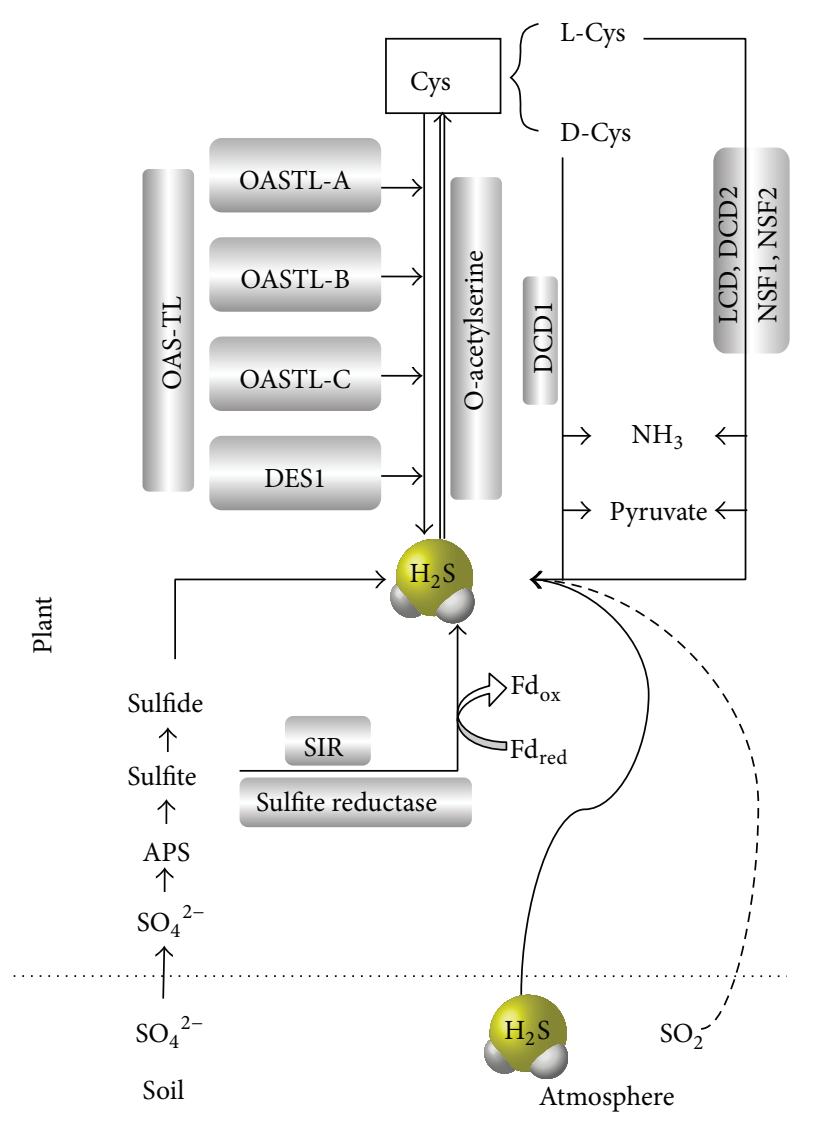

FIGURE 1: An overview of $\mathrm{H}_{2} \mathrm{~S}$ generation in higher plants (adapted from Papenbrock et al., 2007). APS: adenosine $5^{\prime}$-phosphosulfate; $\mathrm{Fd}_{\text {red }}, \mathrm{Fd}_{\mathrm{ox}}$ : reduced and oxidized ferredoxin; SIR: sulfite reductase.

degrades L/D-Cys simultaneously [17, 18]. The production of $\mathrm{H}_{2} \mathrm{~S}$ by $\mathrm{CDes}$ has been confirmed in various areas of biology $[9,11,14,15,19,20]$. CDes are Cys desulfhydrases with singular functions in desulfuration. Their mRNA levels were significantly higher in the stems and cauline leaves than in the roots, rosette leaves, and flowers of A. thaliana [9].

Another class of the enzymes is O-acetyl-L-serine (thiol) lyase (OAS-TL), which is responsible for the incorporation of inorganic $\mathrm{S}$ into Cys, and free $\mathrm{H}_{2} \mathrm{~S}$ appears to be released only in a minor reaction [21]. During an incubation period, the enzyme formed about 25 times more Cys than $\mathrm{H}_{2} \mathrm{~S}$, in a molar ratio, per mg protein [22]. Nine OAS-TL genes have been identified in $A$. thaliana, which are located in the cytosol, mitochondria, or plastid [23]. Recently, DES1 was reported as a frequent novel L-Cys desulfhydrase, which, based on sequence feature alignments, belongs to the OASTL family [24-28]. The Km value for L-Cys in the DES1 reaction is 13 -fold lower than that for OAS in the OAS-TL reaction, indicating a much higher affinity of DES1 for L-Cys as a substrate [2]. The biochemical characterization of the TDNA insertion mutant des1 reveals that the total intracellular Cys concentration increased by approximately 25\% [28]. However, as a member of the OAS-TL family, its function in synthesizing $\mathrm{H}_{2} \mathrm{~S}$ has not been clearly studied. In vitro, the reaction of OAS-TL is a net $\mathrm{H}_{2} \mathrm{~S}$-consuming reaction [22].
TABLE 1: Enzymes and coding genes related to $\mathrm{H}_{2} \mathrm{~S}$ generation in Arabidopsis.

\begin{tabular}{lcccc}
\hline Substrate & Enzyme & $\begin{array}{c}\text { Cellular } \\
\text { localization }\end{array}$ & Locus & Reference \\
& AtLCD & Cytoplasm & At3g62130 & {$[16]$} \\
& AtNFS1/Nifs1 & Mitochondria & At5g65720 & {$[27]$} \\
& AtNFS2/Nifs2 & Plastid & At1g08490 & {$[28]$} \\
L-Cys & DES1 & Cytoplasm & At5g28030 & {$[24]$} \\
& OASTL-A1 & Cytoplasm & At4g14880 & {$[25]$} \\
& OASTL-A2 & Cytoplasm & At3g22460 & {$[30]$} \\
& OASTL-B & Plastid & At2g43750 & {$[26]$} \\
& OASTL-C & Mitochondria & At3g59760 & {$[27]$} \\
\hline D-Cys & AtDCD1 & Mitochondria & At1g48420 & {$[17]$} \\
\hline L/D-Cys & AtDCD2 & Mitochondria & At3g26115 & {$[18]$} \\
\hline \multirow{4}{*}{ Unknown } & PLP-dependent & & & \\
& transferase & Chloroplast & At5g26600 & {$[15]$} \\
& superfamily & & & \\
\hline \multirow{5}{*}{ Unknown } & NAC domain & & & \\
& containing & Unknown & Atlg01010 & {$[15]$} \\
\hline & protein 1 & & & \\
\hline
\end{tabular}

At: Arabidopsis thaliana, Cys: cysteine, DCD: D-Cys desulfhydrase, DES: desulfhydrase, LCD: L-Cys desulfhydrase, NAC: N-acetyl-L-cysteine, NFS: nitrogenase Fe-S cluster, OASTL: O-acetyl-L-serine(thiol)lyase, and PLP: pyridoxal $5^{\prime}$-phosphate.

Thus, the statement that DES1 is the only enzyme involving in the degradation of Cys is open to question [24, 28, 29].

In addition, Nifs/NFS, with L-Cys desulfhydrase-like activity, is also potentially involved in $\mathrm{H}_{2}$ S production $[31,32]$. Two genes, At5g26600 and Atlg01010, in A. thaliana have been identified that encode proteins with CDes structural features [15], and 3-MST is also related to $\mathrm{H}_{2} \mathrm{~S}$ production in plants [33].

\section{Physiological Functions of $\mathrm{H}_{2} \mathrm{~S}$ in Plants}

$\mathrm{H}_{2} \mathrm{~S}$ has been reported to play important roles in diverse physiological processes in plants. Research on the endogenous $\mathrm{H}_{2} \mathrm{~S}$ of higher plants can be traced back to 1978 , when $\mathrm{H}_{2} \mathrm{~S}$ was observed to be released from leaves of cucumber, corn, and soybean [34]. Leaves of older plants contain higher $\mathrm{H}_{2} \mathrm{~S}$ concentrations than younger plants [35]. A recent study showed that the mRNA levels of CDes were gradually elevated in a developmental stage-dependent manner [9]. The importance of $\mathrm{H}_{2} \mathrm{~S}$ in the regulation of plant growth, development, and senescence has emerged.

The improvement in seed germination rates due to exogenous $\mathrm{H}_{2} \mathrm{~S}$ treatments was confirmed. $\mathrm{H}_{2} \mathrm{~S}$ or $\mathrm{HS}^{-}$, rather than other sulfur-containing components derived from the exogenous $\mathrm{H}_{2} \mathrm{~S}$ donor, NaHS, contributed to the promotion of seed germination [4]. NaHS preferentially affects the activity of endosperm $\beta$-amylase and maintains lower levels of malondialdehyde and hydrogen peroxide $\left(\mathrm{H}_{2} \mathrm{O}_{2}\right)$ in germinating seeds [7]. In addition, the application of $\mathrm{NaHS}$ to seedling cuttings of sweet potato promoted the number and length of adventitious roots [5]. At the same time, $\mathrm{H}_{2} \mathrm{~S}$ 
modulates the expression of genes involved in photosynthesis and thiol redox modification to regulate its photosynthesis [36]. It is hypothesized that an increase in the stomatal density also contributes to this process [37]. The osmoticinduced decrease in the chlorophyll concentration could be alleviated by spraying the NaHS solution [6]. $\mathrm{H}_{2} \mathrm{~S}$ was also found to delay flower opening and senescence in cut flowers and branches [8]. These effects occur in a dose-dependent manner. In the cytosol, $\mathrm{H}_{2} \mathrm{~S}$ negatively regulates autophagy and modulates the transcriptional profile of $A$. thaliana using desl [38]. $\mathrm{H}_{2} \mathrm{~S}$ strongly affects plant metabolism at most stages of life and causes statistically significant increases in biomass, including higher fruit yields [39].

$\mathrm{H}_{2} \mathrm{~S}$ also plays pivotal roles in plant responses or adaptation under biotic and abiotic stress conditions. Early studies concerning $\mathrm{H}_{2} \mathrm{~S}$ emissions in plants were associated with plant responses to pathogens as part of sulfur-induced resistance [40]. In 2008, $\mathrm{H}_{2} \mathrm{~S}$ was found to be an important cellular signal for the first time, highlighting the protective effect of $\mathrm{H}_{2} \mathrm{~S}$ against copper stress [4]. Thereafter, a stream of publications on various positive effects of $\mathrm{H}_{2} \mathrm{~S}$ and $\mathrm{H}_{2} \mathrm{~S}$ signaling in plants emerged. Soon, $\mathrm{H}_{2} \mathrm{~S}$ was shown to alleviate the effects of aluminum, cadmium, chromium and boron toxicity, drought and osmotic stress, heat stress, hypoxia, and other stresses [9, 11-13, 20, 41-43]. Most of these reports discussed, as analogies with animal systems, how $\mathrm{H}_{2} \mathrm{~S}$ signaling is important for plant protection against stress.

Stomatal movement is very important in plant responses to environmental stimuli, and a key target of $\mathrm{H}_{2} \mathrm{~S}$ signaling in plants is the specialized guard cell. Recent studies have reported that $\mathrm{H}_{2} \mathrm{~S}$ is responsible for drought stress relief by inducing stomatal closure in $A$. thaliana $[9,20]$. These observations are consistent with a previous report in both Vicia faba and Impatiens walleriana [30]. Similarly, $\mathrm{H}_{2} \mathrm{~S}$ was confirmed to be a novel downstream indicator of nitric oxide (NO) during ethylene-induced stomatal closure [44]. However, the effect of $\mathrm{H}_{2} \mathrm{~S}$ on stomatal movement has been a controversial topic. Another research group reported that exogenous $\mathrm{H}_{2} \mathrm{~S}$ induced stomatal opening by reducing the accumulation of NO in guard cells of A. thaliana and a crop plant, Capsicum annuum $[45,46]$. The reasons for these different observations are not clear and require further study. The difference may simply be due to the different experimental materials and methods. The purpose of stomatal closure is to reduce the moisture loss under drought stress, and the induction of stomatal opening is to enhance photosynthesis and reduce the photorespiration.

\section{Cross-talk of $\mathrm{H}_{2} \mathrm{~S}$ with Other Signals}

Plants perceive and respond to $\mathrm{H}_{2} \mathrm{~S}$, but studies on the mechanisms of $\mathrm{H}_{2} \mathrm{~S}$ functioning in plant responses to stress are very limited. An overview of our current understanding of plant $\mathrm{H}_{2} \mathrm{~S}$ signaling is shown in Figure $2 . \mathrm{H}_{2} \mathrm{~S}$ is particularly active and may interact with and modify numerous other signals. Thus, there may be multiple routes of $\mathrm{H}_{2} \mathrm{~S}$ perception and signaling to be unraveled.

Several lines of evidence point to an interrelationship between $\mathrm{H}_{2} \mathrm{~S}$ and plant hormones in plant defenses. Abscisic acid ( $\mathrm{ABA})$ is produced in large amounts in plants under various abiotic stresses. Under drought stress, the expression of CDes was significantly upregulated, and the production rate of $\mathrm{H}_{2} \mathrm{~S}$ from these plants also increased [9]. Subsequently, the relationship between $\mathrm{H}_{2} \mathrm{~S}$ and $\mathrm{ABA}$ was reported based on a deficiency of $\mathrm{H}_{2} \mathrm{~S}$ in the lcd mutant that had a weakened $\mathrm{ABA}$ induction of stomatal closure, which indicated that the induction of stomatal closure by $\mathrm{ABA}$ was partially dependent on $\mathrm{H}_{2} \mathrm{~S}$. As $\mathrm{H}_{2} \mathrm{~S}$ was also involved in the expression regulation of ion-channel genes, $\mathrm{H}_{2} \mathrm{~S}$ may be a critical component of ABA-induced stomatal closure via ion channels. At the same time, $\mathrm{H}_{2} \mathrm{~S}$ influenced the expression of $\mathrm{ABA}$ receptors, and the influence of $\mathrm{H}_{2} \mathrm{~S}$ may have begun upstream of the ABA signaling pathway. Therefore, the above results showed that $\mathrm{H}_{2} \mathrm{~S}$ interacted with $\mathrm{ABA}$ in the stomatal regulation responsible for drought stress in A. thaliana [20]. Indole acetic acid (IAA) showed a rapid increase in different plants treated by exogenous $\mathrm{H}_{2} \mathrm{~S}$ [5], and ethylene (Eth) could induce $\mathrm{H}_{2} \mathrm{~S}$ generation [44]. In addition, gibberellic acid (GA) and jasmonic acid (JA) were also involved in the $\mathrm{H}_{2} \mathrm{~S}$ signal transduction process. $\mathrm{H}_{2} \mathrm{~S}$ can alleviate the GAinduced programmed cell death in wheat aleurone cells [47], and $\mathrm{H}_{2} \mathrm{~S}$ may function downstream of $\mathrm{H}_{2} \mathrm{O}_{2}$ in JA-induced stomatal closure in $V$. faba [48].

$\mathrm{H}_{2} \mathrm{O}_{2}$ is another signaling molecule in plants, especially in guard cells. Abiotic stress induces synthesis of both $\mathrm{H}_{2} \mathrm{~S}$ and $\mathrm{H}_{2} \mathrm{O}_{2}$; yet it is unclear how these two molecules work in concert in the physiological process. $\mathrm{H}_{2} \mathrm{~S}$ may represent a novel downstream component of the $\mathrm{H}_{2} \mathrm{O}_{2}$ signaling cascade during JA-induced stomatal movement in V. faba [48]. Pretreatment of $\mathrm{H}_{2} \mathrm{O}_{2}$ could improve the germination percentage of Jatropha curcas seeds, and this improvement was mediated by $\mathrm{H}_{2} \mathrm{~S}$ [49]. These results suggest that $\mathrm{H}_{2} \mathrm{O}_{2}$ is upstream of $\mathrm{H}_{2} \mathrm{~S}$. However, there is plenty of evidence to the contrary. $\mathrm{H}_{2} \mathrm{~S}$ inhibited the cadmium influx through the plasma membrane calcium channels, which were activated by $\mathrm{H}_{2} \mathrm{O}_{2}$ [50]. $\mathrm{H}_{2} \mathrm{~S}$ can participate in enhancing plant resistance to abiotic stress via the improvement of antioxidant systems, such as heavy metal stress, osmotic stress, heat stress, and hypoxia stress $[4-7,10,42,43,49]$.

Recent evidence suggests that $\mathrm{H}_{2} \mathrm{~S}$ also plays a role in the $\mathrm{NO}$ and carbon monoxide (CO) signaling pathway. In bermudagrass, sodium nitroprusside (SNP, a NO donor) and NaHS combined treatments showed that NO signaling could be blocked by $\mathrm{H}_{2} \mathrm{~S}$ inhibitors and scavengers, indicating that $\mathrm{NO}$-activated $\mathrm{H}_{2} \mathrm{~S}$ was essential for the cadmium stress response [51]. Additional evidence showed that both NaHS and GYY4137 reduced the NO accumulation to a large extent in $A$. thaliana epidermal cells [45]. In sweet potato seedlings, a rapid increase in endogenous $\mathrm{H}_{2} \mathrm{~S}$ and $\mathrm{NO}$ was sequentially observed in shoot tips treated with NaHS. A similar phenomenon in $\mathrm{H}_{2} \mathrm{~S}$ donor-dependent root organogenesis was observed in both excised willow shoots and soybean seedlings. These results indicated that the process of $\mathrm{H}_{2} \mathrm{~S}$-induced adventitious root formation was likely mediated by IAA and $\mathrm{NO}$ and that $\mathrm{H}_{2} \mathrm{~S}$ acts upstream in IAA and NO signaling transduction pathways [5]. Similarly, heme oxygenase 1 functions as a downstream component in $\mathrm{H}_{2} \mathrm{~S}$-induced adventitious root formation by the modulation 


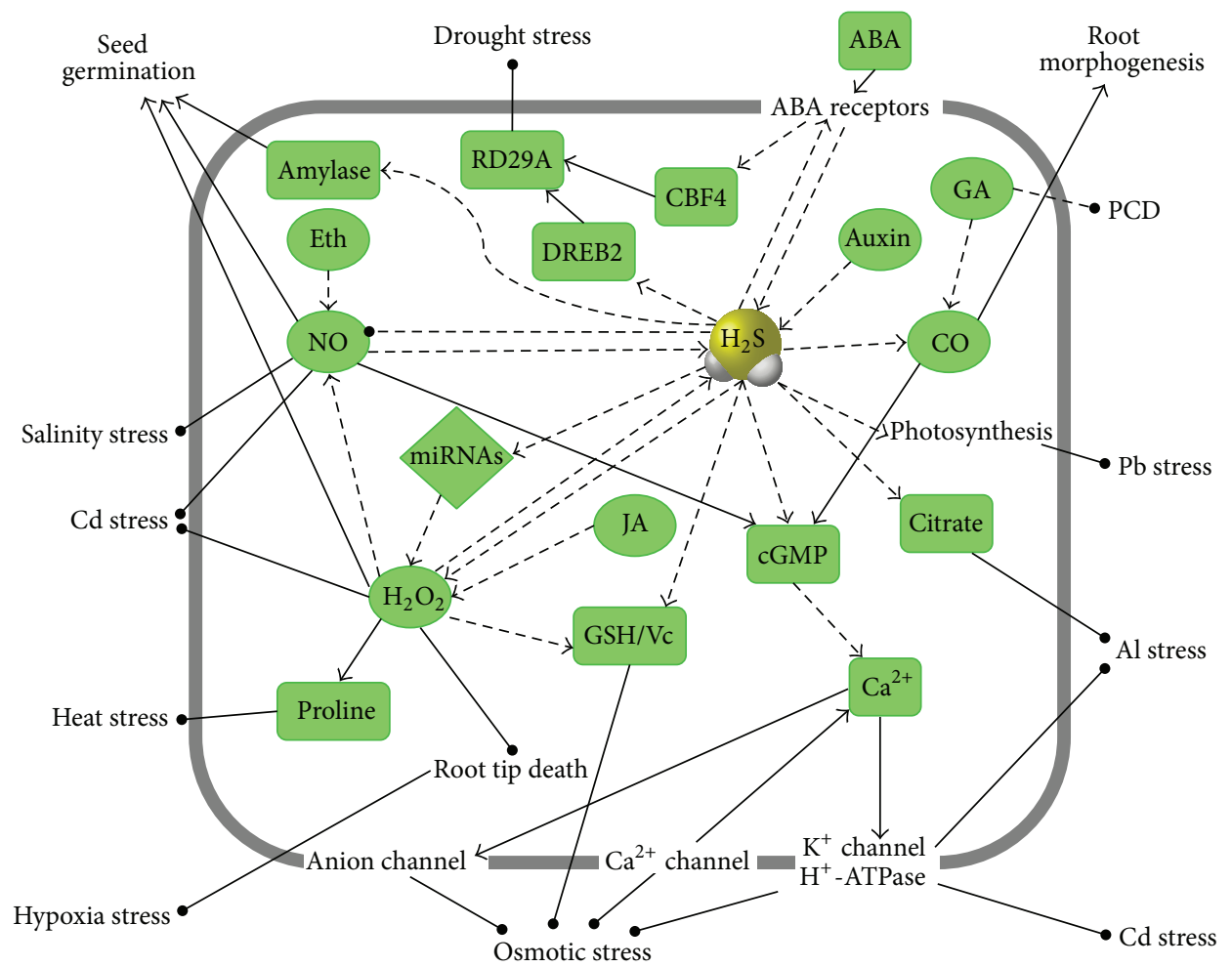

FIGURE 2: Generalized model of $\mathrm{H}_{2} \mathrm{~S}$ signaling in response to abiotic stress in plants. Solid line arrows depict stimulatory effect; dashed cents arrows represent the putative interaction; gray bold rectangle indicates cell membrane. ABA: abscisic acid; CBF: C-repeat binding factor; CO: carbon monoxide; DREB: dehydration responsive element; Eth: ethylene; GA: gibberellic acid; cGMP: cyclic guanosine monophosphate; GSH: glutathione; $\mathrm{H}_{2} \mathrm{O}_{2}$ : hydrogen peroxide; $\mathrm{H}_{2} \mathrm{~S}$ : hydrogen sulfide; JA: jasmonic acid; NO: nitric oxide; PCD: programmed cell death; RD: responsive to desiccation.

of expression of related genes, which suggested that $\mathrm{CO}$ was involved in $\mathrm{H} 2 \mathrm{~S}$-induced cucumber adventitious root formation [52].

Additionally, growing evidence suggests that $\mathrm{H}_{2} \mathrm{~S}$ signaling interacts with calcium $(\mathrm{Ca})$ signaling pathways. $\mathrm{Ca}^{2+}$ confers structure and rigidity to the cell wall and regulates plant processes through calmodulin. Li et al. (2013) showed that NaHS pretreatment could improve the entry of extracellular $\mathrm{Ca}^{2+}$ into tobacco suspension cultured cells mediated by intracellular calmodulin to increase the heat tolerance [41]. At the level of transcription, the expression of $\mathrm{Ca}^{2+}$ channel coding genes decreased, whereas $\mathrm{Ca}^{2+}$-ATPase and $\mathrm{Ca}^{2+}-\mathrm{H}^{+}$ cation antiporters were elevated in the $l c d$ mutant. This was in accordance with stronger $\mathrm{Ca}^{2+}$ fluorescence in the wild type than in the $l c d$ mutant [20]. These results suggest that $\mathrm{Ca}$ signaling plays an important role in the mechanism of $\mathrm{H}_{2} \mathrm{~S}$.

Numerous studies showed that, during the enhancement of plant resistance, many substances changed simultaneously. $\mathrm{H}_{2} \mathrm{~S}$ plays an ameliorative role in protecting plants by increasing the proline content against aluminum toxicity and heat stress $[10,12,41]$. Aluminum-induced citrate secretion was also significantly enhanced by NaHS pretreatment [10]. During the NaHS preincubation period the grain $\beta$-amylase activity increased, improving seed germination [7].

\section{Conclusions and Perspectives}

The mechanisms by which $\mathrm{H}_{2} \mathrm{~S}$ is generated still remain unresolved, and elucidating how it is made by different plant cells under different conditions is clearly a research priority. $\mathrm{H}_{2} \mathrm{~S}$ is a key factor in the tolerance of cells to the oxidative stress induced by a range of abiotic conditions, including heavy metal toxicity, drought and osmotic stress, hot stress, hypoxia and other stresses. This probably involves the activation of antioxidant defenses, the induction of stomatal closure, and the enhanced expression of genes encoding resistanceassociated enzymes. In these processes, plant hormones, $\mathrm{H}_{2} \mathrm{O}_{2}, \mathrm{NO}, \mathrm{CO}$, and Ca signaling participate in $\mathrm{H}_{2} \mathrm{~S}$ signal transduction, resulting in a complex signaling network.

There are numerous unanswered questions and important areas for further research, concentrated in the following areas. (1) Owing to the promiscuous chemical properties of $\mathrm{H}_{2} \mathrm{~S}$, it is problematic to achieve adequate specificity and selectivity for its measurement. At present, the physiological $\mathrm{H}_{2} \mathrm{~S}$ level was measured by various techniques such as the methylene blue method, monobromobimane, gas chromatography, ion selective electrodes, and fluorescent probes [53]. The diverse detection methods resulted in magnitude differences in measured biological sulfide levels, which will certainly attract increasing attention. (2) The 
mechanism of $\mathrm{H}_{2} \mathrm{~S}$ functions performed at the protein level. Until now, a great number of studies focused on protein S-sulfhydration, which is impossible to determine directly by chemical analyses. But in mammals, there have been many results indicating that this process might occur by the transition of intermediate links, such as positional changes and interactions with associated proteins. Moreover, if $\mathrm{H}_{2} \mathrm{~S}$ can thiolate proteins, it may have the same effect on DNA. (3) Even though $\mathrm{H}_{2} \mathrm{~S}$ is a short-lived molecule, it is an extremely active one. The mechanisms by which either $\mathrm{H}_{2} \mathrm{~S}$ or other molecules participating in $\mathrm{H}_{2} \mathrm{~S}$ signaling function are also important. Thus, elucidation of the $\mathrm{H}_{2} \mathrm{~S}$ complex signaling network is clearly a research priority.

\section{Conflict of Interests}

The authors declare that there is no conflict of interests regarding the publication of this paper.

\section{Acknowledgments}

This work was supported by the National Natural Science Foundation of China (31372085 to Yanxi Pei; 31400237 to Zhuping Jin; 31300236 to Zhiqiang Liu) and Shanxi Province Science Foundation for Youths (2014021026-2, to Zhuping Jin).

\section{References}

[1] K. Abe and H. Kimura, "The possible role of hydrogen sulfide as an endogenous neuromodulator," The Journal of Neuroscience, vol. 16, no. 3, pp. 1066-1071, 1996.

[2] W. Zhao, J. Zhang, Y. Lu, and R. Wang, "The vasorelaxant effect of $\mathrm{H}_{2} \mathrm{~S}$ as a novel endogenous gaseous KATP channel opener," The EMBO Journal, vol. 20, no. 21, pp. 6008-6016, 2001.

[3] G. Yang, L. Wu, B. Jiang et al., " $\mathrm{H}_{2} \mathrm{~S}$ as a physiologic vasorelaxant: hypertension in mice with deletion of cystathionine $\gamma$ lyase," Science, vol. 322, no. 5901, pp. 587-590, 2008.

[4] H. Zhang, L.-Y. Hu, K.-D. Hu, Y.-D. He, S.-H. Wang, and J.P. Luo, "Hydrogen sulfide promotes wheat seed germination and alleviates oxidative damage against copper stress," Journal of Integrative Plant Biology, vol. 50, no. 12, pp. 1518-1529, 2008.

[5] H. Zhang, J. Tang, X.-P. Liu et al., "Hydrogen sulfide promotes root organogenesis in Ipomoea batatas, Salix matsudana and Glycine max," Journal of Integrative Plant Biology, vol. 51, no. 12, pp. 1086-1094, 2009.

[6] H. Zhang, Y.-K. Ye, S.-H. Wang, J.-P. Luo, J. Tang, and D.-F. Ma, "Hydrogen sulfide counteracts chlorophyll loss in sweetpotato seedling leaves and alleviates oxidative damage against osmotic stress," Plant Growth Regulation, vol. 58, no. 3, pp. 243-250, 2009.

[7] H. Zhang, W. Dou, C.-X. Jiang, Z.-J. Wei, J. Liu, and R. L. Jones, "Hydrogen sulfide stimulates $\beta$-amylase activity during early stages of wheat grain germination," Plant Signaling and Behavior, vol. 5, no. 8, pp. 1031-1033, 2010.

[8] H. Zhang, S.-L. Hu, Z.-J. Zhang et al., "Hydrogen sulfide acts as a regulator of flower senescence in plants," Postharvest Biology and Technology, vol. 60, no. 3, pp. 251-257, 2011.

[9] Z. Jin, J. Shen, Z. Qiao, G. Yang, R. Wang, and Y. Pei, "Hydrogen sulfide improves drought resistance in Arabidopsis thaliana,"
Biochemical and Biophysical Research Communications, vol. 414, no. 3, pp. 481-486, 2011.

[10] J. Chen, W.-H. Wang, F.-H. Wu et al., "Hydrogen sulfide alleviates aluminum toxicity in barley seedlings," Plant and Soil, vol. 362, no. 1-2, pp. 301-318, 2013.

[11] Y.-W. Li, Z.-H. Gong, Y. Mu et al., "An Arabidopsis mutant atcsr-2 exhibits high cadmium stress sensitivity involved in the restriction of $\mathrm{H}_{2} \mathrm{~S}$ emission," Journal of Zhejiang University: Science B, vol. 13, no. 12, pp. 1006-1014, 2012.

[12] Z.-G. Li, M. Gong, H. Xie, L. Yang, and J. Li, "Hydrogen sulfide donor sodium hydrosulfide-induced heat tolerance in tobacco (Nicotiana tabacum L) suspension cultured cells and involvement of $\mathrm{Ca}^{2+}$ and calmodulin," Plant Science, vol. 185186, pp. 185-189, 2012.

[13] H. Zhang, L.-Y. Hu, P. Li, K.-D. Hu, C.-X. Jiang, and J.-P. Luo, "Hydrogen sulfide alleviated chromium toxicity in wheat," Biologia Plantarum, vol. 54, no. 4, pp. 743-747, 2010.

[14] R. Wang, "Physiological implications of hydrogen sulfide: a whiff exploration that blossomed," Physiological Reviews, vol. 92, no. 2, pp. 791-896, 2012.

[15] J. Papenbrock, A. Riemenschneider, A. Kamp, H. N. SchulzVogt, and A. Schmidt, "Characterization of cysteine-degrading and $\mathrm{H}_{2} \mathrm{~S}$-releasing enzymes of higher plants-From the field to the test tube and back," Plant Biology, vol. 9, no. 5, pp. 582-588, 2007.

[16] H. M. Harrington and I. K. Smith, "Cysteine metabolism in cultured tobacco cells," Plant Physiology, vol. 65, no. 1, pp. 151155, 1980.

[17] A. Schmidt, "A cysteine desulfhydrase from spinach leaves specific for D-cysteine," Zeitschrift für Pflanzenphysiologie, vol. 107, no. 4, pp. 301-312, 1982.

[18] A. Riemenschneider, E. Bonacina, A. Schmidt, and J. Papenbrock, "Remove from marked Records Isolation and characterization of a second D-cysteine desulfhydrase-like protein from Arabidopsis," in Proceedings of the 6th International Workshop on Plant Sulfur Metabolism: Sulfur Transport and Assimilation in Plants in the Post Genomic Era, K. Saito, L. J. de Kok, I. Stulen et al., Eds., pp. 103-106, Chiba, Japan, 2005.

[19] J. J. Shen, Z. J. Qiao, T. J. Xing et al., "Cadmium toxicity is alleviated by AtLCD and AtDCD in Escherichia coli," Journal of Applied Microbiology, vol. 113, no. 5, pp. 1130-1138, 2012.

[20] Z. Jin, S. Xue, Y. Luo et al., "Hydrogen sulfide interacting with abscisic acid in stomatal regulation responses to drought stress in Arabidopsis," Plant Physiology and Biochemistry, vol. 62, no. 1, pp. 41-46, 2013.

[21] C.-H. Tai and P. F. Cook, "O-acetylserine sulfhydrylase," Advances in Enzymology and Related Areas of Molecular Biology, vol. 74, pp. 185-234, 2000.

[22] P. Burandt, J. Papenbrock, and A. Schmidt, "Genotypical differences in total sulfur contents and cysteine desulfhydrase activities in Brassica napus L.," Phyton-International Journal of Experimental Botany, vol. 41, no. 1, pp. 75-86, 2001.

[23] C. Álvarez, L. Calo, L. C. Romero, I. García, and C. Gotor, "An O-Acetylserine(thiol)lyase homolog with 1-Cysteine desulfhydrase activity regulates cysteine homeostasis in Arabidopsis," Plant Physiology, vol. 152, no. 2, pp. 656-669, 2010.

[24] M. Wirtz, M. Droux, and R. Hell, "O-acetylserine (thiol) lyase: an enigmatic enzyme of plant cysteine biosynthesis revisited in Arabidopsis thaliana," Journal of Experimental Botany, vol. 55, no. 404, pp. 1785-1798, 2004. 
[25] E. R. Bonner, R. E. Cahoon, S. M. Knapke, and J. M. Jez, "Molecular basis of cysteine biosynthesis in plants: structural and functional analysis of $\mathrm{O}$-acetylserine sulfhydrylase from Arabidopsis thaliana," The Journal of Biological Chemistry, vol. 280, no. 46, pp. 38803-38813, 2005.

[26] C. Heeg, C. Kruse, R. Jost et al., "Analysis of the Arabidopsis $\mathrm{O}$-acetylserine(thiol)lyase gene family demonstrates compartment-specific differences in the regulation of cysteine synthesis," Plant Cell, vol. 20, no. 1, pp. 168-185, 2008.

[27] J. M. Jez and S. Dey, "The cysteine regulatory complex from plants and microbes: what was old is new again," Current Opinion in Structural Biology, vol. 23, no. 2, pp. 302-310, 2013.

[28] L. C. Romero, I. García, and C. Gotor, "L-cysteine desulfhydrase 1 modulates the generation of the signaling molecule sulfide in plant cytosol," Plant Signaling \& Behavior, vol. 8, no. 5, Article ID e24007, 2013.

[29] L. C. Romero, M. Á. Aroca, A. M. Laureano-Marín, I. Moreno, I. García, and C. Gotor, "Cysteine and cysteine-related signaling pathways in Arabidopsis thaliana," Molecular Plant, vol. 7, no. 2, pp. 264-276, 2014.

[30] C. Gotor, C. Álvarez, M. Á. Bermúdez, I. Moreno, I. García, and L. C. Romero, "Low abundance does not mean less importance in cysteine metabolism," Plant Signaling and Behavior, vol. 5, no. 8, pp. 1028-1030, 2010.

[31] S. Kushnir, E. Babiychuk, S. Storozhenko et al., "A mutation of the mitochondrial $\mathrm{ABC}$ transporter statl leads to dwarfism and chlorosis in the Arabidopsis mutant starik," Plant Cell, vol. 13, no. 1, pp. 89-100, 2001.

[32] S. Léon, B. Touraine, J.-F. Briat, and S. Lobréaux, “The AtNFS2 gene from Arabidopsis thaliana encodes a Nifs-like plastidial cysteine desulphurase," Biochemical Journal, vol. 366, no. 2, pp. 557-564, 2002.

[33] J. Papenbrock, S. Guretzki, and M. Henne, "Latest news about the sulfurtransferase protein family of higher plants," Journal of Amino Acids, vol. 41, no. 1, pp. 43-57, 2011.

[34] L. G. Wilson, R. A. Bressan, and P. Filner, "Light-dependent emission of hydrogen sulfide from plants," Plant Physiology, vol. 61, no. 2, pp. 184-189, 1978.

[35] H. Rennenberg and P. Filner, "Developmental changes in the potential for $\mathrm{H}_{2} \mathrm{~S}$ emission in cucurbit plants," Plant Physiology, vol. 71, no. 2, pp. 269-275, 1983.

[36] J. Chen, F.-H. Wu, W.-H. Wang et al., "Hydrogen sulphide enhances photosynthesis through promoting chloroplast biogenesis, photosynthetic enzyme expression, and thiol redox modification in Spinacia oleracea seedlings," Journal of Experimental Botany, vol. 62, no. 13, pp. 4481-4493, 2011.

[37] B. Duan, Y. Ma, M. Jiang, F. Yang, L. Ni, and W. Lu, "Improvement of photosynthesis in rice (Oryza sativa L.) as a result of an increase in stomatal aperture and density by exogenous hydrogen sulfide treatment," Plant Growth Regulation, vol. 75, no. 1, pp. 33-44, 2014.

[38] C. Álvarez, I. García, I. Moreno et al., "Cysteine-generated sulfide in the cytosol negatively regulates autophagy and modulates the transcriptional profile in Arabidopsis," The Plant Cell, vol. 24, no. 11, pp. 4621-4634, 2012.

[39] F. D. Dooley, S. P. Nair, and P. D. Ward, "Increased growth and germination success in plants following hydrogen sulfide administration," PLoS ONE, vol. 8, no. 4, Article ID e62048, 2013.

[40] E. Bloem, A. Riemenschneider, J. Volker et al., "Sulphur supply and infection with Pyrenopeziza brassicae influence L-cysteine desulphydrase activity in Brassica napus L.", Journal of Experimental Botany, vol. 55, no. 406, pp. 2305-2312, 2004.

[41] Z.-G. Li, X.-J. Ding, and P.-F. Du, "Hydrogen sulfide donor sodium hydrosulfide-improved heat tolerance in maize and involvement of proline," Journal of Plant Physiology, vol. 170, no. 8, pp. 741-747, 2013.

[42] W. Cheng, L. Zhang, C. Jiao et al., "Hydrogen sulfide alleviates hypoxia-induced root tip death in Pisum sativum," Plant Physiology and Biochemistry, vol. 70, pp. 278-286, 2013.

[43] B.-L. Wang, L. Shi, Y.-X. Li, and W.-H. Zhang, "Boron toxicity is alleviated by hydrogen sulfide in cucumber (Cucumis sativus L.) seedlings," Planta, vol. 231, no. 6, pp. 1301-1309, 2010.

[44] J. Liu, L. Hou, G. Liu, X. Liu, and X. Wang, "Hydrogen sulfide induced by nitric oxide mediates ethylene-induced stomatal closure of Arabidopsis thaliana," Chinese Science Bulletin, vol. 56, no. 33, pp. 3547-3553, 2011.

[45] M. Lisjak, N. Srivastava, T. Teklic et al., "A novel hydrogen sulfide donor causes stomatal opening and reduces nitric oxide accumulation," Plant Physiology and Biochemistry, vol. 48, no. 12, pp. 931-935, 2010.

[46] M. Lisjak, T. Teklić, I. D. Wilson, M. E. Wood, M. Whiteman, and J. T. Hancock, "Hydrogen sulfide effects on stomatal apertures," Plant Signaling and Behavior, vol. 6, no. 10, pp. 14441446, 2011.

[47] Y. Xie, C. Zhang, D. Lai et al., "Hydrogen sulfide delays GAtriggered programmed cell death in wheat aleurone layers by the modulation of glutathione homeostasis and heme oxygenase-1 expression," Journal of Plant Physiology, vol. 171, no. 2, pp. 53-62, 2014.

[48] Z. Hou, J. Liu, L. Hou, X. Li, and X. Liu, " $\mathrm{H}_{2} \mathrm{~S}$ may function downstream of $\mathrm{H}_{2} \mathrm{O}_{2}$ in jasmonic acid-induced stomatal closure in Vicia faba," Chinese Bulletin of Botany, vol. 46, no. 4, pp. 396-406, 2011.

[49] Z.-G. Li, M. Gong, and P. Liu, "Hydrogen sulfide is a mediator in $\mathrm{H}_{2} \mathrm{O}_{2}$-induced seed germination in Jatropha Curcas," Acta Physiologiae Plantarum, vol. 34, no. 6, pp. 2207-2213, 2012.

[50] J. Sun, R. Wang, X. Zhang et al., "Hydrogen sulfide alleviates cadmium toxicity through regulations of cadmium transport across the plasma and vacuolar membranes in Populus euphratica cells," Plant Physiology and Biochemistry, vol. 65, pp. 67-74, 2013.

[51] H. Shi, T. Ye, and Z. Chan, "Nitric oxide-activated hydrogen sulfide is essential for cadmium stress response in bermudagrass (Cynodon dactylon (L). Pers.)," Plant Physiology and Biochemistry, vol. 74, pp. 99-107, 2014.

[52] Y.-T. Lin, M.-Y. Li, W.-T. Cui, W. Lu, and W.-B. Shen, "Haem oxygenase-1 is involved in hydrogen sulfide-induced cucumber adventitious root formation," Journal of Plant Growth Regulation, vol. 31, no. 4, pp. 519-528, 2012.

[53] P. Nagy, Z. Pálinkás, A. Nagy, B. Budai, I. Tóth, and A. Vasas, "Chemical aspects of hydrogen sulfide measurements in physiological samples," Biochimica et Biophysica Acta, vol. 1840, no. 2, pp. 876-891, 2014. 


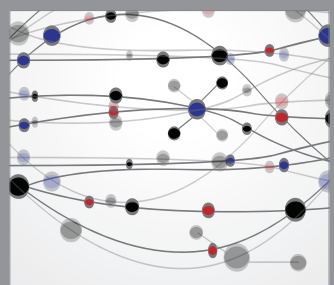

The Scientific World Journal
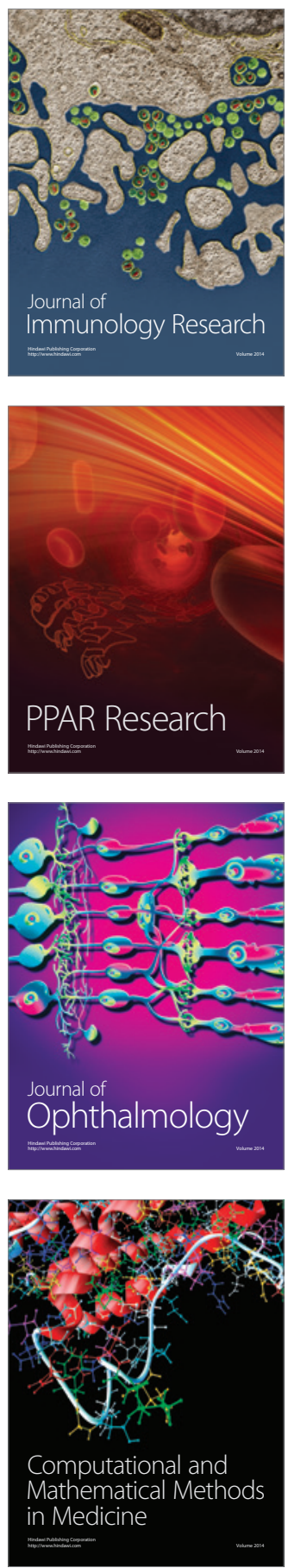

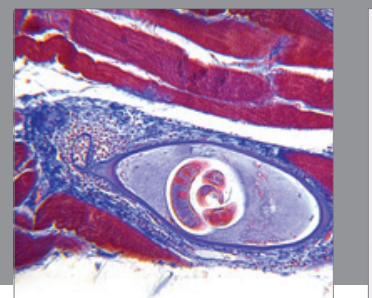

Gastroenterology

Research and Practice
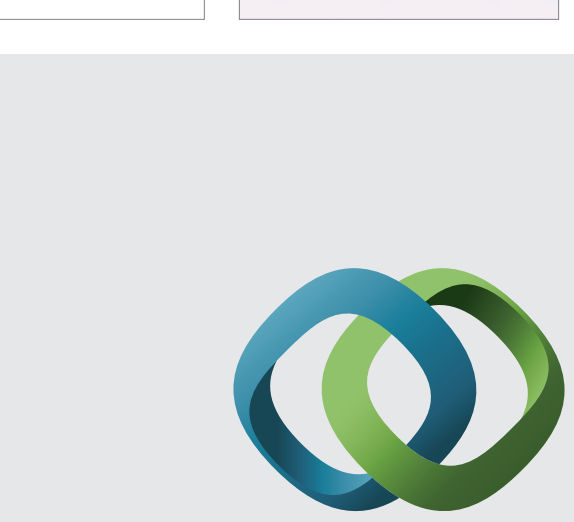

\section{Hindawi}

Submit your manuscripts at

http://www.hindawi.com
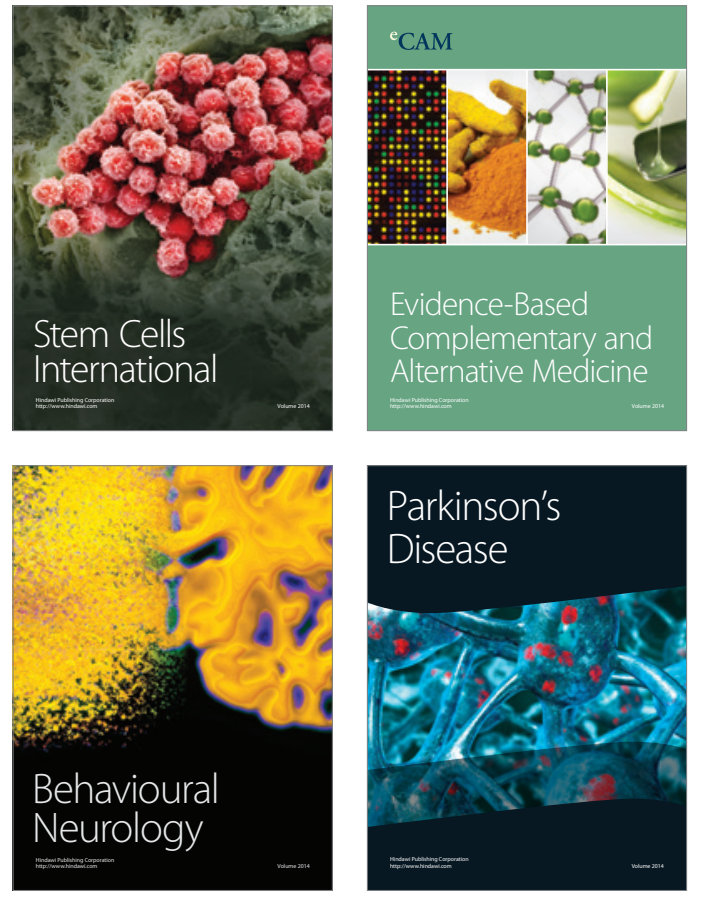
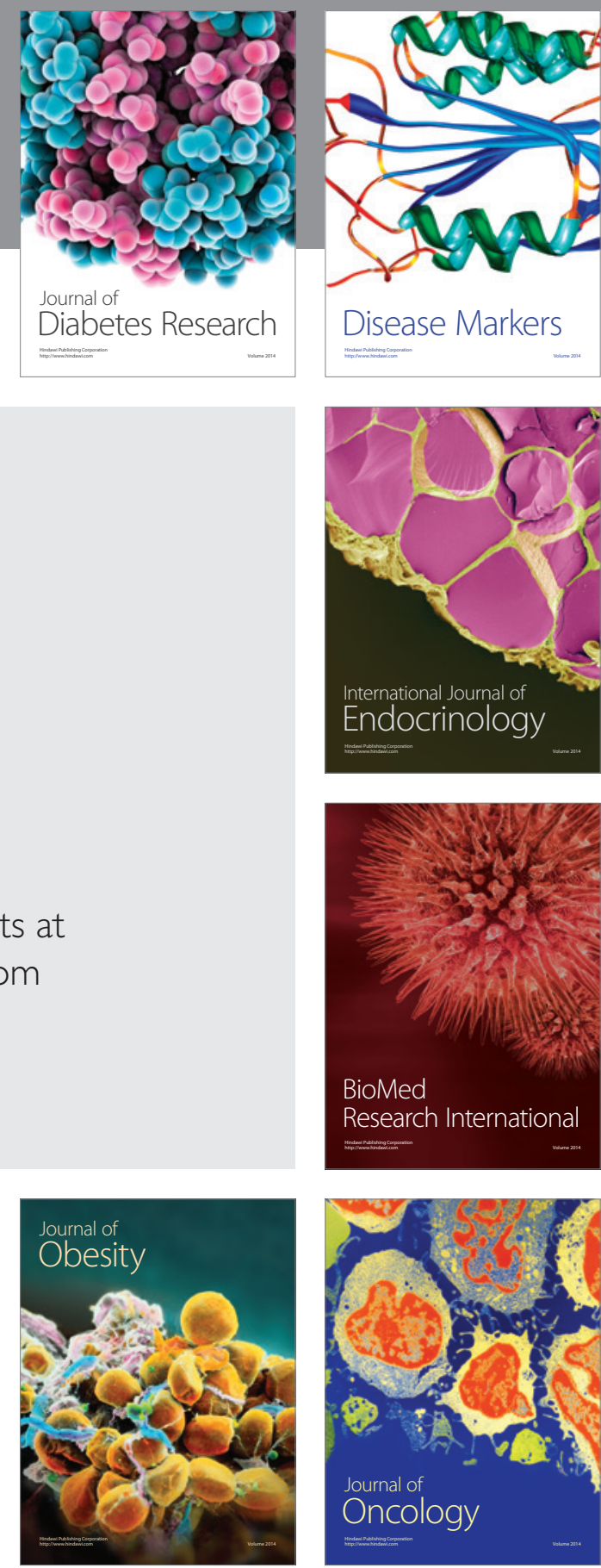

Disease Markers
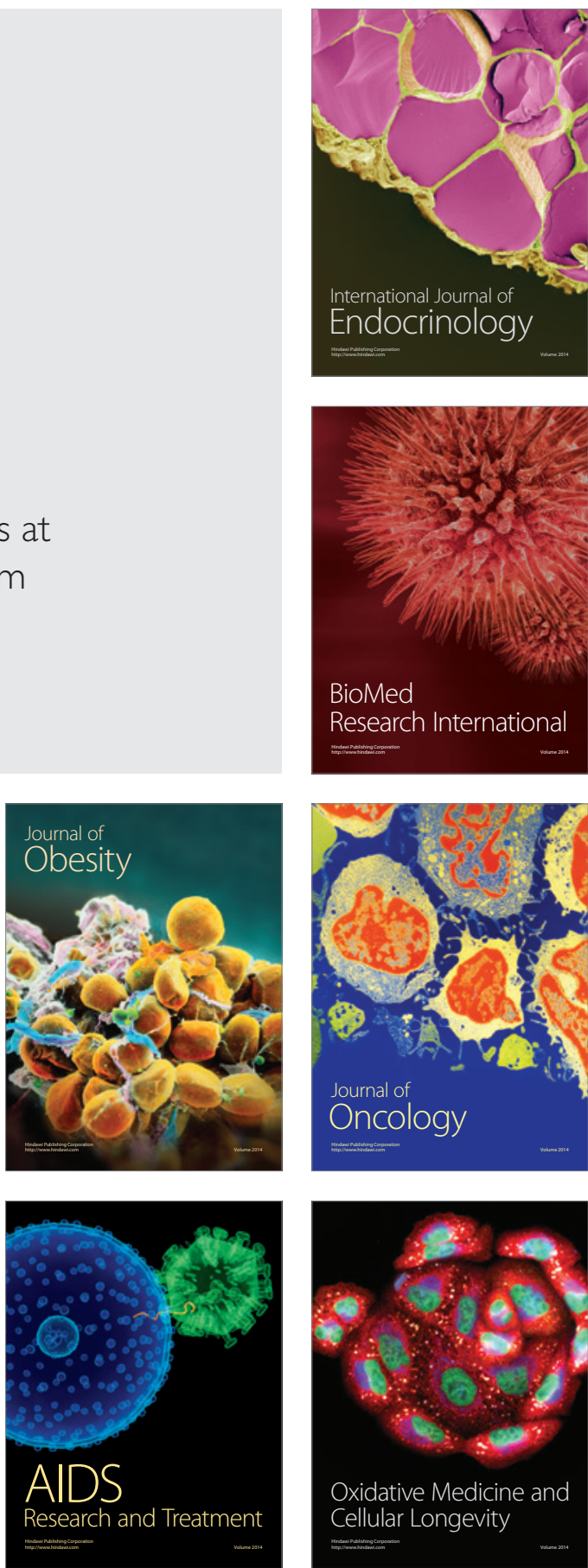